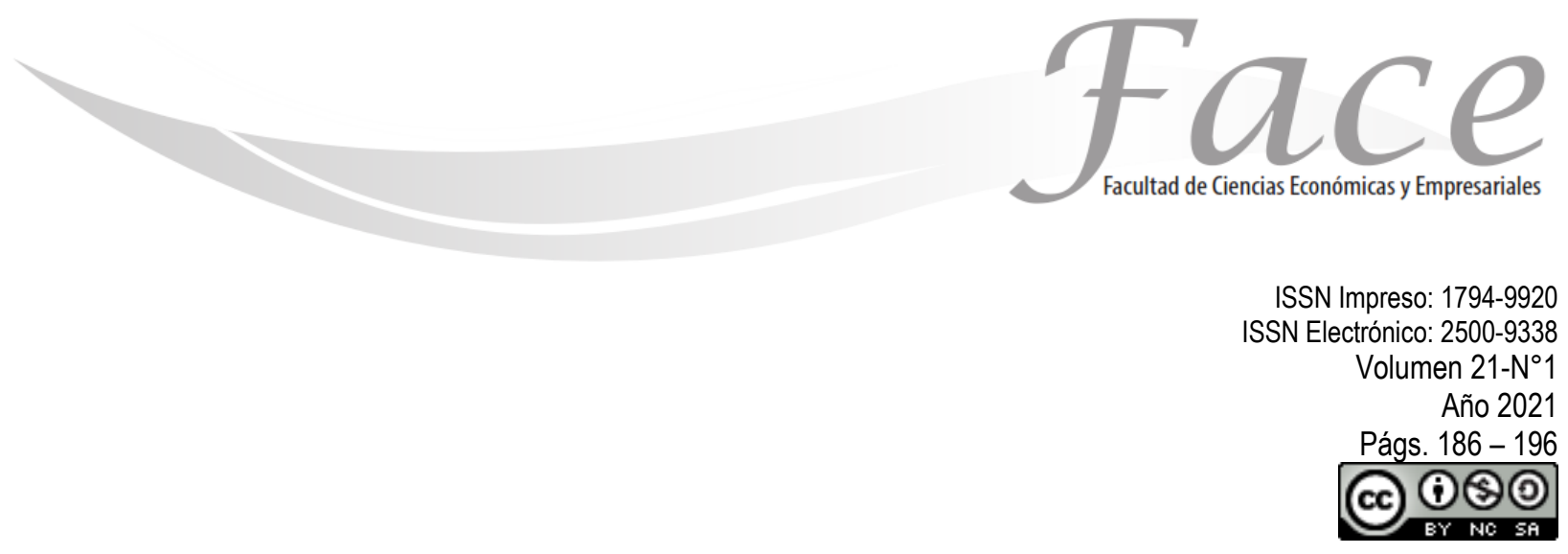

\title{
RESPONSABILIDAD ÉTICA: ESTRATEGIA EN LA HUMANIZACIÓN DE LAS UNIVERSIDADES
}

\author{
Annherys Paz Marcano * \\ Enlace ORCID: https://orcid.org/0000-0001-7538-1563 \\ Alain Castro Alfaro ** \\ Enlace ORCID: https://orcid.org/0000-0002-7247-7073 \\ Edith Pinto Aragón *** \\ Enlace ORCID: https://orcid.org/0000-0003-4698-2268
}

Fecha de Recepción: Marzo 5 de 2021

Fecha de Aprobación: Julio 10 de 2021

\section{Resumen:}

La responsabilidad ética, se sustenta como una estrategia que guía la actuación de los colaboradores en la gestión institucional, con reglas, valores y normas que contribuyen a la excelencia de su trabajo. Es así como este artículo analizo la responsabilidad ética como estrategia en la humanización de las universidades. Teniendo como metodología, una tipología analítica, descriptiva, documental argumentado del diseño bibliográfico. A manera de reflexión final, la responsabilidad ética en las universidades, constituye una estrategia axiología que orienta el comportamiento de su gente en el desempeño de sus actividades, contribuyendo a la gestión desde un modelo humanizado que agregar valor en la transparencia de los procesos académicos, investigativos, extensionista y administrativos, los cuales facilitan el alcance de los indicadores por una gestión de excelencia y calidad, que sustenta la bases misiones en la moral y los valores compartidos en el trabajo.

. Palabras clave: Responsabilidad ética, estrategia, moral, valores, humanización, colaboradores, Universidades

* Post-doctora Gerencia de las organizaciones. Postdoctorado Integración y desarrollo en Latinoamérica. Post-doctora Gerencia Pública y Gobierno. Doctora Administración. Magíster Gerencia de Recursos Humanos. Licenciada en Administración de Empresas. Docente e Investigadora de la Universidad de La Guajira, Colombia. Grupo de investigación AIKA, categoría A avalado por Colciencia. Investigador Senior. ** Doctorante en Socioformación y Gestión del Conocimiento (Centro Universitario CIFE - México). Magister Gestión de Alta Dirección. (Universidad Federico Villarreal, Perú). Sociólogo. (Universidad Inca Garcilaso de la Vega, Perú). Director General e Investigador del Centro de Investigaciones y Capacitaciones Interdisciplinares SAS. Contacto: director@centrodeinvestigacionescic.com.co - Docente investigador y Editor de la Revista Aglala de la CURN, Cartagena, Colombia. Grupo de Investigación CURN Cartaciencia. Investigador Asociado Minciencias. Contacto: alain.castro@curnvirtual.edu.co

*** Contador Público. Magister Gerencia de Recursos Humanos. Especialista en Auditoria de calidad y cuentas médicas. Docente e investigador de La Universidad de La Guajira. Colombia. Grupo de investigación Cañaguate. Contacto: : apintoa@uniguajira.edu.co. 


\title{
ETHICAL RESPONSIBILITY: STRATEGY IN THE HUMANIZATION OF UNIVERSITIES
}

\begin{abstract}
:
Ethical responsibility is sustained as a strategy that guides the actions of collaborators in institutional management, with rules, values and norms that contribute to the excellence of their work. This is how this article analyzes ethical responsibility as a strategy in the humanization of universities. Having as a methodology, an analytical, descriptive, documentary typology based on the bibliographic design. As a final reflection, ethical responsibility in universities constitutes an axiology strategy that guides the behavior of its people in the performance of their activities, contributing to management from a humanized model that adds value in the transparency of academic processes, investigative, extensionist and administrative, which facilitate the achievement of the indicators for a management of excellence and quality, which sustains the mission bases in morale and shared values at work.
\end{abstract}

Keywords: Ethical responsibility, strategy, moral, values, humanization, collaborators, Universities

\section{RESPONSABILIDADE ÉTICA: ESTRATÉGIA NA HUMANIZAÇÃO DAS UNIVERSIDADES}

\section{Resumo:}

A responsabilidade ética sustenta-se como estratégia que norteia as ações dos colaboradores na gestão institucional, com regras, valores e normas que contribuem para a excelência do seu trabalho. É assim que este artigo analisa a responsabilidade ética como estratégia na humanização das universidades. Tendo como metodologia, uma tipologia analítica, descritiva, documental baseada no desenho bibliográfico. Como reflexão final, a responsabilidade ética nas universidades constitui uma estratégia axiológica que norteia o comportamento de suas pessoas no desempenho de suas atividades, contribuindo para a gestão a partir de um modelo humanizado que agrega valor na transparência dos processos acadêmicos, investigativos, extensionistas e administrativos, que facilitem o alcance dos indicadores para uma gestão de excelência e qualidade, que sustente as bases da missão na moral e nos valores partilhados no trabalho.

Palavras-chave: Responsabilidade ética, estratégia, moral, valores, humanização, colaboradores, Universidades 


\section{INTRODUCCIÓN:}

El hombre, como agente social constituye la fuente de talento humano, que vitaliza el sistema laboral que engrana los procesos medulares en la gestión organizacional, representando un factor que sustenta el quehacer de las actividades, por tanto, su actuación cumple un rol de colaborador en la dinámica estratégica que guía el alcance de los objetivos planificados para la competitividad en el sector donde ejerce su actividad. Según Alles (2005), las competencias que distingue la fuerza de trabajo en las organizaciones comprenden el instrumento competitivo en su razón de ser.

Por tal razón, el hombre en el desempeño de sus procesos laborales esta condicionada por las capacidades manifiesta de sus competencias, el cual se ve reflejado en los resultados empresariales, siendo aprovechadas en sus quehaceres, por lo que su actuación se convierte en un indicador de la dinámica institucional, con la experticia de habilidades, destrezas y valores, que argumenta la acción ética moral, conllevando a un modelo axiológico para un entorno humanizado. A su vez, hay que tener presente que se puede obtener ventajas competitivas por medio de la información dando valor agregado diferenciados tanto en su oferta de productos como en la prestación de un servicio (Agredo, 2019).

Para Hamburger (2009) las características distintivas del humanismo empresarial, radica en la sensibilidad del hombre hacia su entorno, a través de una noción axiológica en su relación como persona consigo mismo y otros, siendo un ser genuino e irremplazable empleando el bien en todo acto humano. Sobre este particular, expresan Bermejo y Villacieros (2018) que la humanización empresarial, parte de impregnarla de los valores genuinamente humanos, el cual trasciende en su práctica en el actuar social, utilizando el bien.

Al respecto, el mercado empresarial, sin exclusión de las universidades hacen ineludible la humanización en el entono laboral, con el reconocimiento que los colaboradores, son un factor dinámico que fortalecen el desarrollo del trabajo en la cotidianidad institucional, por tanto son el potencial de sus habilidades y competencias las que enriquecen el alcance de los indicadores de gestión; de esta manera su actuación se convierte en el pilar de la praxis de valores, que conceden la identidad y el compromiso responsable y ético. Para, Alvira (2006) la humanización empresarial crea un un estilo humano de vida, el cual hace que el hombre sea el punto de referencia de la empresa. En otras palabras, ubica a las personas como agente humana donde confluye su comportamiento en lo humano al servicio de sí mismo y los de su entorno. Esto va de la mano con lo expresado por Alzamora (2016), cuando dice que son trascendentales los principios de equidad, reciprocidad y conveniencia nacional con el fin de buscar el fomento de las interrelaciones económicas.

Desde este este escenario, las tendencias en la gestión universitaria, hace énfasis que el comportamiento humano, coadyuva con la formalidad en la asignación de tareas, favoreciendo desde su cargo en la obtención de la excelencia institucional, donde su obrar se articula con valores que fortalecen la cultura organizacional creando y sentido responsable. Menciona Ramos (2006), que la responsabilidad, es la facultad del ser humano para captar una obligación, y su cumplimiento depende de la autonomía moral que comprobara su fijación personal.

En este sentido, según Robbins y Coulter (2014), la responsabilidad, es una aptitud individual, innegable en el crecimiento y progreso de toda persona, sustentado en el margen de sus acciones, procesos y en consecuencias en los actos aun pesar de no ser aceptados. Plantea, Savater (2000) que la responsabilidad es una actitud, de carácter individual dentro del comportamiento social del hombre.

A su vez, la responsabilidad social empresarial es una exigencia ética y una manera estratégica racional de buscar el desarrollo para la inteligencia organizacional donde se permeen sus procesos por medio de la búsqueda de sí misma como de su retribución a la sociedad (Palma, Caycedo, Guzmán, Varon, Ruiz, 2019; Díaz y Bernal, 2017; Zapata, Restrepo, Galindo, Hernández, Franco y Genez, 2021).

Por consiguiente, un ambiente humanizado en las universidades, propicia actitudes de trabajo que se distinguen por prácticas creativas, innovadoras, transparentes, emprendedoras, íntegras, flexibles y comprometidas con la razón de ser institucional, robusteciendo de este modo, la visión ética 
colaborativa argumentada en valores para crear ambientes de convivencia. Según Guédez (2008) la ética, comprende el hacer humano del hombre; por su parte, Cortina (1999) la ética orienta la actuación del hombre, alistándolo para cumplir con su rol en la vida. Por tanto, agregan Paz, Harris y Molero (2010) que la ética, descansa en el comportamiento moral de las personas, y es guiado por un marco normativo para desenvolverse en el campo personal y profesional.

Entonces se infiere, que la ética guía el camino del ser humano en su intervención en la sociedad, siendo su actuación el núcleo axiológico para cristalizar el desenvolvimiento como agente que nutre la responsabilidad ante la toma de decisiones, y ejerciendo su participación transparente que impacta en la calidad y competitividad institucional. Según Martín (2006), la ética apunta a situaciones humanas concretas, siendo un enfoque axiológico garante de la vida. Por su parte, Castro, Paz y Pinto (2020) la gestión institucional, comprende un rol ético e integrador, como filosofía de trabajo, que fomenta la identidad cultural transparente ante un compromiso participativo entre los colaboradores y la institución.

Entonces, puede decirse que la actitud del ser humano intuye el principio regente del comportamiento ante el bien o el mal, siendo el manifiesto sobre lo que se hace, cómo se hace, por qué se hace y ante lo que se dice, representando la fuerza interior la base que controla el obrar de la condición innata que le pertenece; por ello, hablar de acto humano, viene hacer el complemento del comportamiento ético fundado en la voluntad del ser humano para cumplir su rol de vida, donde en el contexto universitario, no puede verse como un criterio aparte, ya que es el cimiento del compromiso e identidad cultural de los colaboradores, el cual crea un ambiente holístico en la gestión de valores institucionales. La Declaración mundial de la educación superior de la UNESCO (1998, citado de Paz, et al 2013) expresa en su articulado número 2, que las universidades deben cumplir un rol y compromiso ético en sus funciones sustantivas.

No obstante, las universidades no solo suelen ser unidades conductoras del saber social, sino también fuentes de cambios y transformación que aporten a la construcción de sociedades humanizadas y sostenibles, por lo que deben debe crear cambios de paradigma para asumir retos y mitigar los obstáculos que deterioran el desarrollo. En virtud de ello, expresan
Horta y Rodríguez (2006), que el hombre es una persona única y autónoma, por ello es incomparable, presenta aptitudes y actitudes individuales que 10 hacen único, por lo que sus actos suelen ser buenos 0 malos.

Desde los aspectos planteados, se desglosa, que cada ser humano tiene una personalidad propia, lo cual lo distingue como ser genuino, estructurado de competencias innatas y técnicas conseguidas de la formación y experticia profesional, por lo que su actuar de manera ética lo hace un ser humano integro. Para Savater (1999), la ética es una convicción humana, que diferencia una acción para elegir entre un acto bueno o malo, donde de manera personal el hombre eligen cual tomar. Según Paz, et al (2010) la ética en la gestión universitaria, transciende las bases del desempeño institucional, ya que ella se debe al comportamiento de los colaboradores con la práctica valores responsables.

Por su parte, Robbins y Coulter (2014) manifiestan que la ética, son reglas, principios, pautas que definen la conducta buena y mala del ser humano, explica la moral, evitando expresar qué ha de hacer $u$ omitir ante cualquier situación dada en la vida. Soto y Cárdenas (2007) señalan que la ética son preceptos axiológicos que distinguen entre una actuación bien 0 mal, se trata de discernir entre lo correcto e incorrecto, por tanto, justifican la aplicación ante una acción u acto. En este particular, la ética se comporta como una instancia estratégica que orienta al hombre en lo social pero también en su desempeño institucional vislumbrando la base de su hacer en los actos axiológicos, en el que los valores lo llevan a que actué desde su juicio interior y regido voluntad propia y responsable.

De allí, que la ética sea una concepción humana que modela la vida del hombre, por lo que, en universidades, los colaboradores deben propiciar en su ambiente laboral tanto el compromiso como un desempeño ético, respaldado por el ejercicio inequívoco de la transparencia, y, en consecuencia, la práctica de valores, para conseguir los objetivos institucionales. Según, Robbins y Coulter (2014) los valores comprenden evidencias sobre un acto correcto e incorrecto, siendo en la práctica institucional, los que orientan el quehacer humano para desarrollar acciones e interactuar en función de lograr objetivos. Para Chiavenato (2009) un valor, comprende la creencia acerca de lo que se puede concebir o no, es decir, lo 
que es o no imprescindible, por ello orienta el comportamiento de las personas.

Por consiguiente, el vínculo colaborador institución argumenta la base misional para obtener el bien común, y el desarrollo integral de ella, desde una responsabilidad ética. Por esta razón, los valores son pautas universales que sustentan la actuación de las universidades, demostrado que dinamizan la vida laboral, con el compromiso con su gente y el entorno. Es de este modo, como el plan estratégico de las universidades, debe contener en su estructura principios éticos para el fomento de un ambiente humanizado que garantice su visibilidad en el cumplimiento de sus actividades tanto internas como externas, donde la responsabilidad ética cultive la identidad en el trabajo para ser competitiva. Chiavenato (2009) los valores, son la base de la cultura organizacional.

Dentro de este marco, los valores éticos edifican el comportamiento de los colaboradores en las universidades, pudiendo con su actuación aportar a un ambiente humanizado basado en la responsabilidad ética. Menciona, Colmenares (2003) los valores, son principios morales que coadyuvan la disposición tanto del comportamiento como las relaciones del hombre en la sociedad, siendo el sostén de la ética. Asimismo, coincide Guedez (2008) que los valores éticos, aluden a guiar el comportamiento del ser humano, apoyando su relación con el entorno, desde una base ética. En virtud de los aspectos planteados, el artículo tiene como objetivo analizar la responsabilidad ética como estrategia en la humanización de las universidades, constituyendo el cimiento que guía el comportamiento de los colaboradores en la gestión institucional.

\section{MARCO TEÓRICO}

\section{RESPONSABILIDAD ÉTICA: SUSTENTO DE LA ACTUACIÓN MISIONAL DE LAS UNIVERSIDADES}

La universidades como agentes proactivos en la formación del hombre, deben aportar al progreso sostenible de la nación haciéndola más humana, por lo que su actuación deben emprenderse con la estructuración de normas y principios éticos- morales, para diferenciarse en el mercado académico, siendo capaz de fomentar cambios que aperturen la adquisición de ventajas competitivas, ya que su éxito y estabilidad va depender de diversos factores como: el humano, la tecnología, la innovación, la creatividad y calidad de los procesos de trabajo, entre otros, pero también en su declaración humanizada, siendo visible en la cultura de identidad, el cual se comporta como el cimiento de un compromiso ético, con alcance compartido de los colaboradores de la institucional. Coincide Hernández, Villalobos, Morales y Moreno (2016) que el sector universitario debe garantizar la competitividad y adaptación a las transformaciones del sistema educativo y la sociedad, a través de la humanización de sus procesos.

He allí que la ética en las universidades define la cultura institucional como un principio que orienta los valores de los colaboradores, frente a la concepción de la vida, el hombre, juicios, hechos, y la moral. Para Álvarez, Cerda, Huerta y León (2010) la responsabilidad, la ética y la moral universitaria, es la base misional que contribuye al desarrollo de los valores y atributos propios de su responsabilidad en términos éticos y estratégicos.

Dentro de este marco, las universidades establecen principios éticos con una responsabilidad compartida, que ayuda a forjar la calidad de vida de sus colaboradores y el servicio ofertado en la sociedad, es decir, suscitando la convivencia y el bienestar en el entorno de ellas. Guedez (2006), define responsabilidad como la idoneidad humana para responder por lo que se hace o se deja de hacer, y en efecto respondiendo por las consecuencias derivadas de sus actos.

En virtud de ello las universidades, constantemente debe asumir un compromiso de comunicación transparente en sus funciones misiónales, con la praxis de la responsabilidad ética, como elemento de una cultura de valores para lograr un tejido humanizado. Para Cortina (2001) la responsabilidad ética, viene hacer el respeto por el dialogo, para conseguir el bien común entre los grupos de intereses, y construir una arquitectura ética. Del mismo modo, para Pelekais, et al (2007) la responsabilidad ética, tiene su razón de ser en la responsabilidad social, representando el compromiso para atender los problemas de la sociedad y construirla con esquemas sostenibles, transparentes, democráticos, sustentables y solidarios. Asimismo, Pelekais y Aguirre (2008) expresan que la 
responsabilidad ética se estructura de valores que orienta la gestión empresarial.

Por otro lado, las instituciones universitarias no pueden dejar de lado que el ecosistema sigue un curso alarmante de deterioro y la ética debe permear el comportamiento profesional para que se pueda respetar el desarrollo sostenible (Franco y Gómez, 2019; Hernández, Franco, Canabal, Sánchez y D'Andreis (2017).

A modo general, la responsabilidad ética en universidades debe asumirse como una estrategia que orienta las acciones destinadas a crear un compromiso compartido en los colaboradores, siendo imparcial y objetivo en el quehacer de sus funciones, y guiado por un liderazgo ético que armonice los ambientes mediante la convivencia e integración de valores e $n$ sus funciones sustantivas. A su vez, Martínez, Barbosa, Amaya y Guzmán (2020), dicen que aún hay mucho por investigar y conocer sobre ventaja competitiva y la responsabilidad social corporativa. De esta manera, se expone que la responsabilidad ética en las universidades, debe ser un componente de la gerencia estratégica para agregar valor en la obtención de los indicadores de calidad y la satisfacción por el bien común.

\section{DESEMPEÑO ÉTICO RECTITUD DE LA GESTION UNIVERSITARIA}

En la gestión inequívoca de las universidades, se debería reflexionar acerca del desempeño ético institucional, en el cual los tiempos de cambios emergentes, requieren de la transformación de escenarios humanizados mediante la formación de valores en los colaboradores como pilares de la actuación laboral que agregan valor desde sus ideas, pero al igual donde los resultados de sus ocupaciones den lugar a la imagen corporativa ganando reputación ante los grupos de interés y con ello generar competitividad.

Bajo este planteamiento, se puede afirmar que el desempeño ético en las universidades más que un resultado en la medición de los indicadores de gestión, derivado de las actividades del quehacer de ella, ofrece en los colaboradores un marco referencial como elemento de rectitud para la construcción de instituciones éticamente responsables y humanas, siendo el lugar de partida en el respeto hacia los valores como: la responsabilidad, libertad, solidaridad, paz, justicia, equidad, transparencia y dignidad por el trabajo, en tal caso no se trata de elegir un valor en su actuar sino hacerlo parte del compromiso hacia la conducta de vida.

De acuerdo a los criterios de Guedez (2006) el desempeño ético del hombre estriba en la forma autónoma, madura y adulta de concebir el resultado de sus actos. Por su parte, Holden (2001) el desempeño ético es un reflejo de los principios morales, de reglas que se escogen para practicar el juego de la vida, su objetivo se concentra en la búsqueda de la justicia, la verdad, valores y principios.

En consecuencia, los valores se comportan como los supuestos que guían e impulsan la actuación de los colaboradores en las universidades, otorgando sentido de pertenencia, y estableciendo los compromisos éticos entre ellos; además de orientar desde el principio de responsabilidad las acciones sobre cómo actuar e interactuar para contribuir con los objetivos trazados. En este sentido, los objetivos precisan los resultados a lograr en la organización, mientras los valores orientan el cómo conseguirlos.

Atendiendo a lo planteado, los valores institucionales se basan en fuentes universales que ayudan a establecer una regla de vida, instituyendo niveles de responsabilidad y compromiso en los colaboradores, no solo en los espacios de trabajo sino como ente coparticipe de la sociedad. Por consiguiente, el nivel de conciencia en la persona con respecto a sus valores, permitirá la regulación y autocontrol de las situaciones que pudiesen suscitarse en el entorno laboral.

De esta manera se alude la interrogante ¿el hombre nace ético o aprende ser ético?, para dar respuesta a ello se explica el postulado de Sábato (1999) que el hombre no hereda reglas morales, solo adquiere capacidades de respuesta hacia estímulos y preceptos de reacción, condicionado en el ambiente en el cual se desenvuelve. A razón de ello, el desempeño ético en las universidades, es el resultado de la actuación de los colaboradores, sustentado de la ocupación en responder por el compromiso de sus principios éticos morales, que fortalecen la cultura ética entre las relaciones con las personas de su entorno. Según Sábato (1999), el hombre nace dotado de criterios auténticos, el cual implica un comportamiento 
sereno, valido, confiable, sincero y sensible, tanto en su condición personal como ente social.

Por ello, se infiere que el desempeño ético viene acompañado de una responsabilidad ética en la gestión universitaria, ya que sus colaboradores como entes sociales se preocupan por alcanzar los objetivos institucionales que generen competitividad desde los resultados de su actuación, mostrando preocupación por mantener la excelencia institucional, pero también la calidad de vida de todos para alcanzar el bien común, es decir desde sus aportes ser el constructor de espacios de convivencia para la sustentabilidad para un hoy y un mejor mañana.

\section{CULTURA ORGANIZACIONAL: ELEMENTO DE LA RESPONSABILIDAD ÉTICA UNIVERSITARIA}

La cultura organizacional propende el cimiento de la identidad institucional, conjugando la difusión e intervención de creencias, actitudes, principios entre otros, representando en conjunto la guía que otorga coherencia a los colaboradores; además de crear un compromiso personal ante las normas, valores y formas de pensar que caracterizan el comportamiento en todos los niveles de la estructura organizacional, donde a la vez muestra al contexto exterior el rostro humano de identidad como imagen de la misma, y con ello forja la estabilidad en el mercado. Para Newstrom (2011) la cultura organizacional, es la integración de valores, tradiciones, creencias, hábitos, normas, actitudes y conductas que hacen marchar la dinámica organizacional, a favor de contribuir en beneficio de las metas y objetivos en común. Desde estas perspectivas, se infiere que generar una cultura ética donde se persiga una consciencia de lealtad, confianza, vitalidad, participación, comunicación, entre otros valores que guía la conducta de compromiso de los colaboradores en la institución.

Dentro de este marco, la cultura organizacional como cimiento de la responsabilidad ética universitaria, se percibe como el reflejo emitido por la médula institucional, estando comprometida en el desarrollo de las actividades realizada por los colaboradores, acompañado de las estrategias para obtener resultado favorables, donde su actuación se convierte en las huellas de identidad responsable siendo el corazón que ejerce vida propia, estando complementada de los propósitos estratégicos de manera transparente, por tanto es el tejido que sensibiliza la construcción de su personalidad y la expresión de un lenguaje propio.

Para Chiavenato (2009) la cultura organizacional, estructura los valores que sitúan la organización y sus colaboradores. Asimismo, Werther y Davis (2008) la gente que se identifica con la cultura organizacional, genera sentido de pertenencia en cualquier espacio de ella. Coinciden Reyes y Moros (2019), que la cultura organizacional, integra el sistema de significado, que vitaliza la dinámica empresarial, siendo reconocida y compartida por todos sus colaboradores, por lo que se puede expresar que el clima organizacional es un elemento importante para aquellos que tengan una visión de aumentar la productividad (Cardona, Lamadrid y Brito, 2018). En este sentido, desde el contexto universitario la cultura organizacional, establece comportamientos éticos que cultivan la identidad y relaciones de convivencia e integración en los colaboradores, siendo un patrón que evoluciona y crea ventajas distintivas.

\section{METODOLOGÍA:}

\section{DESCRIPCIÓN METODOLÓGICA.}

Este artículo, desde el quehacer científico, se desarrolló mediante técnicas metodológicas con la revisión y recolección de información, siendo sus actividades conducentes a la compilación y argumentación de criterios para conseguir la respuesta al objetivo de estudio. Según Hernández, Fernández, Baptista (2014) la recolección de datos, implica la estructura de un plan, que especifica de manera organizada las actividades y procedimientos a llevar a cabo para lograr los fines, por lo cual fue creado. Por su parte, Arias (2016) que las técnicas de recolección de datos, son diversas al momento de buscar información de interés para desarrollar el estudio, por lo que el uso de su tipología queda a juicio de investigador y sus intereses particulares.

Atendiendo el objetivo que representa este estudio, la investigación es analítica explicativa, interpretando la información recogida de los supuestos teóricos relativos al tema sobre la responsabilidad ética como principio rector en universidades. Según Bernal (2010) la investigación analítica se le al igual como como explicativa, teniendo como eje central el estudio del porqué de las cosas, hechos, fenómenos o situaciones. Asimismo, Hurtado (2012), refiere que 
interpreta o analiza la información siguiendo algunos criterios, dependientes de los objetivos en estudio.

Por otro lado, se trata de un estudio descriptivo, en el cual se abordan evidencias particulares de la temática investigada, en este caso en universidades. Según Méndez (2013), que la investigación descriptiva sienta sus bases en criterios distintivos en elementos, componentes y su interrelación, por lo que su razón de ser se indaga en los hallazgos implicados en el estudio. Para Hurtado (2012) la investigación descriptiva, alude a la representación de hechos presentes en el estudio.

A los efectos de la recolección de información, se empleó la técnica bibliográfica también denominada fuente secundaria, acudiendo a la revisión y consulta de información de autores acerca de la temática de investigación diseminada en diversos productos científicos, como textos, proyectos, tesis, monografías, artículos, entre otros. De acuerdo a Méndez (2013), las fuentes documentales o secundarias, son aquellas disponibles en bibliotecas a través de libros, periódicos y otros materiales documentales como trabajos de grado, revistas especializadas, entre otros, sirviendo de material de consulta sobre la temática de estudio. Del mismo modo, coincide Arias (2016) que la investigación documental es ser la consulta de información procedentes de materiales tanto impresos como otros tipos de documentos científicos.

\section{CONCLUSIONES}

\section{REFLEXIONES FINALES}

La rapidez como emanan las transformaciones en el entorno mundial, propician la adaptabilidad de tendencias en los diversos sectores que dan vida a la economía de las naciones, sin ser lejanos de lo que acontecen y se ve reflejado en la vida de las universidades, las cuales demandan cambios y adaptación de procesos constantes para responder a los requerimientos del entorno, siendo sus estrategia la base que orienta la gestión institucional con una arquitectura axiológica de valores compartidos para la praxis de la responsabilidad ética en el cumplimiento de las funciones de los colaboradores, siendo corresponsables en la comunidad universitaria.
De tal modo que, las universidades como células del saber, habrán de propiciar la humanización social, mediante el fomento de valores ético-morales, en las actividades de su quehacer académico, investigativo, de proyección social y administrativas para obtener la excelencia y calidad institucional, aunado a fomentar una cultura ética responsable que contribuye forjar espacios más sostenibles y humanos.

En este sentido, las universidades como fuente de humanización social dirigen sus acciones en una gestión en un desempeño ético, para la construcción de cultura de valores con identidad que acompañe al ADN institucional integrado por hombres responsables y convencidos, que esta se engendra a partir de un patrón axiológico colaborativo con proyección a todos los grupos de interés. Es decir, con visión de identidad, donde el dominador común sea maximizar la expresión universitaria caracterizándose por la responsabilidad ética en su quehacer misional como fuente de vitalidad, en el cual coexisten líderes éticos integrados para dar respuesta a las necesidades de la sociedad, con justicia, solidaridad, paz, tolerancia, respeto en virtud del desarrollo de la calidad de vida por el bien común, convirtiéndose de instituciones tradicionales en instituciones humanas éticamente responsable de su actuación consigo misma y otros.

En tanto, las universidades en su rol de servicio a la sociedad deben fundamentar su actuación en una cultura ética, que propicie un sentido de trabajo humanizado para alcanzar los indicadores de gestión y con ello el éxito desde su responsabilidad ante la comunidad institucional, el cual vitalice su potencialidad con un desempeño que valoren lo que hacen, como lo hacen y el para que se hace; de esta manera fortalece su compromiso e identidad propia, hacia el bien común.

Por otro lado, corresponde entonces a los directivos de las universidades nutrir la actuación de los colaboradores en sus tres pilares de docencia, investigación y extensión, asimismo la actividad administrativa mediante la divulgación y practicidad de principios, patrones y códigos de ética, siendo difundidos los valores con la introducción de acciones que garantizan el desarrollo humano, siendo coparticipes en la construcción de un futuro mejor, donde se beneficie no solo a los colaboradores de la institución como pilar del saber social sino de humanización al servicio de todos. 
Entonces, la cultura como cimiento de la responsabilidad ética universitaria, habrá de difundir los valores institucionales, conllevando al sustento de un ambiente de identidad humanizado mediante el modelaje de patrones de comportamientos en las funciones de trabajo; en otras palabras, fomentando la inserción de valores en el quehacer diario para favorecer el cambio de actitudes; además, de contribuir en la relaciones de los colaboradores en un entorno de convivencia colectiva, a fin de obtener ventajas competitivas desde un ambiente gratificante, respetuoso y humanizado.

\section{REFERENCIAS:}

Álvarez, Juan; Cerda, Hugo; Huertas, María y León Adalberto (2010) La responsabilidad ética y social universitaria. Mito o Realidad. Colombia. Editorial Universidad Cooperativa de Colombia.

Agredo Satizábal, F. (2019). Impacto de las TIC en la competitividad empresarial soportada por un modelo de educación digital. Enfoque Disciplinario, 4(1), 37-50. Recuperado a partir de

http://enfoquedisciplinario.org/revista/index.php lenfoque/article/view/20

Alvira, R. (2006). Dimensiones estéticas de la empresa. Cuadernos, empresa y humanismo. No. 67,

pp. $4-13$ https://core.ac.uk/download/pdf/83556239.pdf

Alles, M. (2005). Dirección estrategia del recurso humano. Gestión por competencias. Argentina. Editorial Granica

Arias, F (2016). El Proyecto de Investigación. Venezuela. Editorial Episteme. Sexta Edición.

Alzamora Taborda, E. (2016). Impacto de las prácticas de auditoría en la disminución de fraude en las organizaciones. Enfoque Disciplinario, 1(1), 3540. Recuperado a partir de http://enfoquedisciplinario.org/revista/index.php lenfoque/article/view/7
Bermejo, J. C., \& Villacieros Durban, M. (2018). Humanización y acción. Revista Iberoamericana De Bioética, (8), 01-16. https://doi.org/10.14422/rib.i08.y2018.005

Bernal, C (2010). Metodología de la Investigación para la Administración y Economía. Santa Fe de Bogotá DC. Colombia. Editorial Pearson

Castro-Alfaro, A., Paz-Marcano, A. I., \& Pinto-Aragón, E. E. (2020). Ética profesional en empresas de servicios de telefonía móvil en Venezuela. Aibi Revista De investigación, administración $E$ ingeniería, 8(3), 87-96. https://doi.org/10.15649/2346030X.876

Cardona Arbelaez, D., Lamadrid Villarrreal, J., \& Brito Carrillo, C. (2018). La gestión y dirección del talento humano desde el análisis sobre clima organizacional y sus dimensiones. Un estudio de caso. Aglala, 9(1), 154-176. https://doi.org/10.22519/22157360.1185

Chiavenato, I (2009) Comportamiento Organizacional La dinámica del éxito en las organizaciones. México. Editorial Mc. Graw Hill Interamericana Editores, S.A. Segunda Edición.

Colmenares, P (2003) Valores y Ética. Colombia editorial Mac Graw Hill segunda edición

Cortina, A (2001) Comunidad Política y Comunidad Ética. En alianza y contrato. Madrid. Trotta.

Cortina, A (1999) Ética en la empresa. España. Ediciones Simancas

Del Franco Blanco, L., \& Gómez Lorduy, A. (2019). Contabilidad ambiental. Una reflexión en el marco de la gestión socialmente responsable de las empresas colombianas. Aglala, 10(2), 60-80 Recuperado de http://revistas.curnvirtual.edu.co/index.php/agla la/article/view/1432

Díaz Ortíz, A., \& Bernal Payares, O. (2017). Caracterización del estado de responsabilidad social empresarial en los hoteles cinco estrellas de la ciudad de Cartagena - Caso hotel Holiday Inn Morros Cartagena. Conocimiento Global, 2(1), 56-63. Recuperado a partir de http://conocimientoglobal.org/revista/index.php/ cglobal/article/view/16 
Franco-Blanco, Liliana y Machado-Licona, jhorquis. (2020). Responsabilidad Social Universitaria: formación, investigación y cooperación como estrategias de desarrollo sostenible. Experiencias significativas en Instituciones de Educación Superior en Cartagena de Indias Colombia . En Meriño, V., Martínez, E., \& Martínez, C. (Ed.) .Gestión del Conocimiento. Perspectiva Multidisciplinaria". Vol. 26, Año 2020, , Pág. 461-477. Santa Bárbara - Zulia Venezuela: Fondo Editorial Universitario de la Universidad Nacional Experimental del Sur del Lago de Maracaibo Jesús María Semprúm. https://www.cedinter.com/review/gestion-delconocimiento-perspectiva-multidisciplinariavolumen-26/

Guédez, V (2006) Ética práctica de la Responsabilidad Social Empresarial Editorial Planeta Venezolana, Venezuela.

Guedez, V. (2008). Ser confiable. Responsabilidad social y reputación empresarial. Caracas. Editorial Planeta.

Hamburger, A. (2009). Ética y responsabilidad social: imperativos de las empresas modernas. Bogotá, Colombia. Revista Gestión \& Sociedad. Pp.155-165. Universidad de San Buenaventura.

Hernández, R; Fernández, C Y Baptista; M (2014) Metodología de la Investigación. México. Editorial Mc. Graw Hill Interamericana Editores, S.A. Sexta Edición.

Hernández, P; Villalobos, V; Morales, M y Moreno, J (2016) Racionalismo emergente en la gerencia universitaria: factor de humanización en universidades de Colombia, Venezuela y México. Venezuela. Revista Espacios. Vol. 37 (№ 30) Año 2016. Pág. 1. https://www.revistaespacios.com/a16v37n30/1 6373001.html

Hernández Royett, J., Franco, D., Canabal Guzmán, J., Sánchez Otero, M., \& D'Andreis Zapata, A. (2017). La auditoría ambiental, una atribución de las funciones del revisor fiscal. Aglala, 8(1), 219-242.

https://doi.org/https://doi.org/10.22519/221573 $\underline{60.1033}$
Holden, P (2001) Ética de Managers. Madrid. Ediciones Paidós Ibérica

Horta, E y Rodríguez, V (2006). Ética general. Bogotá. Eco ediciones. Sexta edición

Hurtado, J (2012) El proyecto de Investigación. Comprensión holística de la Metodología y la investigación. Venezuela. Ediciones Quirón. Sypal, Servicios y proyecciones para América Latina. Séptima edición ampliada

Martin, V (2006) El Fortalecimiento Ético de las instituciones del Ámbito Público en América Latina. Panel de Crisis Ética Latinoamericana y Fortalecimiento de las Organizaciones Públicas. Ponencia presentada en el VIII Congreso Internacional del CLAD sobre la Reforma del Estado y de la Administración Pública Panamá.

Martínez Amado, W. E., Barbosa Guerrero, L. M., Amaya Cocunubo, I. F., \& Guzmán Ramos, H. F. (2020). ¿Son los momentos de crisis, una oportunidad para las marcas?. Enfoque Disciplinario, 5(2), 19-23. Recuperado a partir de

http://enfoquedisciplinario.org/revista/index.php /enfoque/article/view/22

Méndez, C (2013) Metodología diseño y desarrollo del proceso de investigación. Colombia. Editorial Llimusa.

Newstrom, J (2011). Comportamiento Humano en el trabajo. México. Editorial McGRAWHill//nteramericana Editores, S.A. DE C.V. Décimo tercera edición

Palma Cardoso, E., Caycedo Riaño, M., Guzmán, R. A., Varón Giraldo, O., \& Ruíz Conde, S. (2019). Estrategias de mejoramiento a partir de la responsabilidad social y ambiental en los procesos de producción en la agroindustria arrocera del sur oriente del Tolima. Aglala, 10(2), 38-59. http://revistas.curnvirtual.edu.co/index.php/agla la/article/view/1431

Paz, A; Núñez, M; Salom, J y Rosales, V (2013) Responsabilidad social universitaria: Moralidad o compromiso en la formación de valores éticos en la educación de futuro. Revista Opción de la 
Universidad del Zulia Venezuela. Año 29, Numero 72. 2013. pp.97-116

Paz, A; Harris., J y Molero, L (2010) Ética fundamento de la responsabilidad social universitaria. Ponencia presentada en la II Jornadas Científicas Internas de la Universidad Dr. José Gregorio Hernández. 9,10 y 11 de noviembre de 2010. Difusión de saberes en el Mundo Globalizado. Venezuela, Maracaibo Estado Zulia

Pelekais, C. y Aguirre R. (2008) Hacia Una Cultura de Responsabilidad Social México. Ediciones Pearson. Primera edición.

Pelekais, C; Ferrer, J; Cruz, A; Romero, D (2007) Responsabilidad social compromiso de las organizaciones. Venezuela. Ediciones Astro Data, S. A

Ramos, M. (2006). Valores y Autoestima. Conociéndose a sí mismo en un mundo con otros. Venezuela. Editorial San Pablo.

Reyes Hernández, Javier, \& Moros Fernández, Helena. (2019). La cultura organizacional: principales desafíos teóricos y metodológicos para su estudio. Revista Estudios del Desarrollo Social: Cuba y América Latina , 7(1), 201-217. Epub 01 de septiembre de 2019. Recuperado en 11 de agosto de 2021, de http://scielo.sld.cu/scielo.php?script=sci_arttext \&pid=S2308$01322019000100201 \& \operatorname{lng}=e s \& t \mid n g=e s$

Robbins, S y Coulter, M (2014). Administración. México. Editorial Pearson Education. Decimosegunda edición

Sábato, E (1999) Formación de Ciudadanía e Identidades. Argentina. Editorial Globo

Salas de Gómez, N. M. (2018). Desarrollo social de la nueva PDVSA: una mirada desde la perspectiva cualitativa - Primera Parte. Enfoque Disciplinario, 3(1), 18-47. Recuperado a partir de

http://enfoquedisciplinario.org/revista/index.php lenfoque/article/view/11

Savater, F (2000) Ética y Ciudadanía Revista de Humanidades: Tecnológico de Monterrey, núm.
8, 2000, pp. 155-172. Instituto Tecnológico y de Estudios Superiores de Monterrey Monterrey, México.p.155-172

https://www.redalyc.org/pdf/384/38400809.pdf

Soto, E. y Cárdenas, J. (2007). Ética en las organizaciones. México. Editorial McGraw-Hill Interamericana Editores, S.A. Primera edición.

UNESCO (1998). Declaración Mundial sobre la Educación Superior en el Siglo XXI. Aprobada por la Conferencia Mundial sobre Educación Superior celebrada en la ciudad de Paris. Disponible en: http://www.unesco.org/education/educprog/wc he/declaration_spa.htm. Consultado el $\underline{30.06 .2011 .}$

Werther, W. y Davis, K. (2008) Administración de personal y Recursos Humanos. México. Editorial Mc Graw Hill Interamericana. Sexta edición

Zapata, A., Restrepo, S., Galindo-Cárdenas, S., Hernández-Royett, J., Franco-Campos, D. y Genez, Liliana (2021). Capítulo 3. Análisis del comportamiento ético del contador público colombiano, Cap 3 pp. 62-96. En Aproximaciones al ejercicio ético del profesional contable, un análisis desde el aula de clases. Available from: https://www.researchgate.net/publication/3511 35214 Capitulo 3 Analisis del comportamien to etico del contador publico colombiano 